\title{
O JOGO COMO CONTEÚDO DA EDUCAÇÃO FÍSICA E SUAS POSSIBILIDADES CO-EDUCATIVAS
}

\author{
Junior Vagner Pereira da Silva, Universidade Estadual de Santa Cruz - UESC, Bahia - Brasil \\ Tânia Mara Vieira Sampaio, Universidade Estadual de Santa Cruz - UESC, Bahia - Brasil
}

\section{RESUMO}

Observado não só entre humanos, mas também entre animais, historicamente diferentes significados têm sido atribuído ao jogo, seja em relação ao local de sua realização, objetivos ou organização. Em relação ao local de realização, embora a rua por muito tempo tenha figurado como palco do jogo, sobretudo entre crianças, que por lá jogavam, se divertiam e se desenvolviam, sua ocorrência também se estende à outros contextos, dentre eles a escola. Contudo, se no contexto informal o jogo é realizado pelo simples prazer, ou seja, é o jogo pelo jogo, no âmbito escolar, sobretudo nas aulas de Educação Física, sua aplicação na mesma perspectiva não se justifica, pois sub-entende que caracterizada como componente curricular obrigatório da Educação Básica e o jogo como conteúdo, a Educação Física tem saberes a serem trabalhados. Desta forma, este estudo tem como objetivo refletir sobre o jogo como conteúdo da Educação Física e suas possibilidades co-educativas.

Palavras-Chave: Educação Física; Jogo; Co-educação.

\section{HOW THE GAME CONTENT OF PHYSICAL EDUCATION AND CO- EDUCATIONAL OPPORTUNITIES}

\begin{abstract}
Observed not only among humans but also among animals, historically different meanings have been attributed to the game, whether in relation to the place of its performance, goals or organization. In relation to the venue of, although the street has long figured as a stage of the game, especially among children who were playing there, had fun and developed, its occurrence also extends to other contexts, including school. However, in the informal context the game is played for the sheer pleasure, or is the play by play, in schools, especially in physical education classes, in the same way your application is not justified, because that means sub-characterized as mandatory component of basic education curriculum and the game as content, physical education knowledge has to be worked. Thus, this study aims to reflect on the game as the content of physical education and its possibilities co-educational.
\end{abstract}

Key-Words: Physical Education Game, Co-education. 


\section{INTRODUÇÃO}

Em Homo Ludens, uma das mais clássicas obras a respeito do jogo, Huizinga ${ }^{1}$ defende a perspectiva de que o jogo antecede a cultura, pois sua manifestação não se limita aos humanos, sendo também observado entre animais. Em que pese o jogo, enquanto elemento da cultura, como defende Huizinga, e suas possibilidades de ocorrência, também se dar entre os animais, parece-nos razoável entendermos que é entre os humanos que o jogo ganha diferentes significados e que é na infância que sua manifestação encontra espaço privilegiado. Porquanto o jogo, nessa fase, encontra-se presente constantemente, seja por intermédio de um pedaço de papel, uma madeira, um lápis, um alimento, um chinelo, uma escada, com seu corpo, dentre várias possibilidades que, simbolizadas, transformam-se em objeto de jogo, o que permite à criança ser eximia conhecedora da arte do jogar. E, ainda, sua manifestação se dá pelo domínio de vários jogos já existentes, pela criação de seus próprios jogos, pela recriação de regras ou pelo conhecimento das diferentes variações de um mesmo jogar.

É neste contexto que o jogo ganha destaque e passa a fazer parte do conhecimento de grande parte da sociedade, pois quem não foi criança e carrega consigo boas experiências sobre esta arte? Desta forma, por ter feito parte da vida e da experiência das pessoas é comum, no cotidiano, que muitos assumam o papel de "conhecedores do jogo". Essa condição foi observada, em diversas ocasiões na atuação docente nas séries iniciais do Ensino Fundamental, algo que, muito possivelmente, também tenha sido verificado por outros profissionais da área.

Devido às aulas de Educação Física serem frequentemente realizadas ao ar livre (quadras, pátios, gramados, praças etc.), o trabalho executado fica exposto a todos que por esses espaços, ou próximos a eles, circulam, e, constantemente, o docente é interpelado por pessoas de diversas áreas de atuação que por lá passam sobre a facilidade de atuar na Educação Física, devido ao jogo fazer parte dos conteúdos a serem ministrados e, com frequência, estar presente nas aulas. Assim, frases como: "Ser professor de Educação Física é fácil, só brinca, né?”; “Ah, eu também gostaria de ser professor de Educação Física, pois só dá joguinho”; "Ser professor de Educação Física é fácil, pois só fica brincando" são comuns, fazendo com 
que o trabalho desenvolvido com o jogo no âmbito da Educação Física sofra uma vulgarização de significado.

A respeito das interpretações feitas sobre o jogo, Caillois ${ }^{2}$ corrobora expondo que frequentemente esse termo evoca ideias de facilidade, descontração, diversão, não seriedade, percepções essas observadas nas características apresentadas por Huizinga ${ }^{1}$ como sendo do jogo.

\begin{abstract}
Numa tentativa de resumir as características formais do jogo, poderíamos considerálo uma atividade livre, conscientemente tomada como "não séria" e exterior à vida habitual, mas ao mesmo tempo capaz de absorver o jogador de maneira intensa e total. É uma atividade desligada dentro de limites espaciais e temporais próprias, segundo uma certa ordem e certas regras. Promove a formação de grupos sociais com tendência a rodearem-se de segredo e a sublinharem sua diferença em relação ao resto do mundo por meio de disfarces ou outros meios semelhantes. ${ }^{1: 16}$
\end{abstract}

Mediante essa forma de pensar, o jogo ocorreria pela evasão do mundo real, isolado das atividades fecundas, e que, encarado como uma mera distração se manifestaria como uma atividade livre, com lugar e duração própria, ocorrendo sua adesão pelo simples gosto de jogar. ${ }^{1}$ Em outras palavras, "só se joga se quiser, quando se quiser e o tempo que se quiser". ${ }^{1-}$ 2:27

Concordamos com as considerações de Huizinga ${ }^{1}$ e Caillois ${ }^{2}$ no que tange às características apresentadas em relação ao jogo, no entanto, é preciso salientar que o jogo se traduz em diferentes significados, havendo necessidade da distinção entre o jogo realizado no contexto informal (defendido pelos autores) e o jogo enquanto conteúdo da Educação Física, pois embora no âmbito da escola características importantes e inerentes ao jogo, como a ludicidade, alegria e descontração devam ser mantidas, sua manifestação não poderá ocorrer numa perspectiva do "jogo pelo jogo", descompromissada de um objetivo a ser alcançado, pelo menos para o docente, que deve dispor de um conjunto de conhecimentos que fundamentem sua atuação e justifiquem a sua atuação profissional.

Entende-se, com isso, que, a exemplo do que ocorre em outras disciplinas e em conteúdos da própria Educação Física, ao recorrer o jogo como conteúdo, a prática pedagógica docente deve estar fundamentada em diferentes princípios e conhecimentos e, dentre eles, os relativos aos sujeitos do processo ("para quem ensinar"), aos conteúdos a serem trabalhados ("o que ensinar"), às estratégias mediadoras do ensino/aprendizagem (“como ensinar") 3 e aos 
objetivos que se pretende alcançar com os conteúdos e estratégias utilizadas ("para que ensinar"), logo, o jogo não ocorrendo simplesmente pelo jogo.

Assim exposto, o jogo neste trabalho, destinado à Educação Física, é concebido como atividade motora composta por um conjunto de regras temporárias, uma vez que está passível de influência pelo estudante como agente transformador, realizados individualmente ou em equipes, com locais, materiais e objetivos previamente definidos, configurando-se em momento privilegiado à ocorrência do lúdico, manifestado pelo prazer, alegria, descontração e felicidade.

Em relação a "para quem ensinar", tornam-se necessários conhecimentos sobre as diferentes fases de desenvolvimento humano ao longo da vida, as faixa etárias predominantes de ocorrência e suas características, como as do desenvolvimento cognitivo - sensório-motor (de zero a 2 anos), pré-operatório (de 2 a 7 anos), operatório-concreto (de 7 a 12 anos) e operatório-formal (a partir de 12 anos), ${ }^{4}$ crescimento físico-pré-natal (da concepção ao nascimento), primeira infância (do nascimento aos 2 anos), infância (de 2 a 10 anos), adolescência (de 10 a 20 anos), adulto jovem (de 20 a 40 anos), meia-idade (de 40 a 60 anos) e idade terciária (acima de 60 anos), ${ }^{5}$ e desenvolvimento motor-movimentos reflexos (de 4 meses intra-uterino a 1 ano), movimentos rudimentares (de 1 a 2 anos), movimentos fundamentais (de 2 a 7 anos) e movimentos esportivos (acima de 7 anos). ${ }^{5}$

No que se refere às fases de desenvolvimento humano, é importante lembrar que diversas críticas recaem sobre elas, por articularem determinadas características humanas a uma faixa etária. Contudo, cabe ressaltar que as fases de desenvolvimento e as faixas etárias neste trabalho são entendidas como características com probabilidades maiores de ocorrerem em uma determinada faixa etária e importante de conhecê-las, porém, não limitadas a eles, uma vez que aspectos relacionados ao contexto ambiental/cultural, como maiores estímulos às atividades físicas e motoras, oportunidades de convívio social, exposição a situações problemas, tipo de educação formal, dentre outros, são aspectos que podem favorecer a ocorrência dessas características antecipadamente, como a restrição pode levá-las ao surgimento mais tardio. Assim, ressaltamos que há uma íntima relação entre princípios universais do desenvolvimento humano e os princípios individuais, fazendo com que tanto a 
cultura familiar quanto a escolar tenham grande influência sobre o desenvolvimento do indivíduo.

Neste sentido, conhecer as características mais globais do grupo em que se está trabalhando é essencial para que a prática pedagógica seja executada passo a passo, a fim de melhor atender a população-foco da atuação, permitindo aos espaços, materiais esportivos e regras dos jogos, num primeiro momento, serem adequados às capacidades físicas, motoras e cognitivas dos sujeitos, para que a complexidade da tarefa a ser aplicada não seja fácil demais a ponto de não provocar nenhuma dificuldade e nem difícil demais a ponto de dificilmente se obter sucesso com a realização da mesma.

Contudo, por outro lado, devemos estar atentos também aos ensinamentos de Vygotsky ${ }^{6}$ em relação à importância do processo educacional ir além do que a criança já é capaz de resolver sozinha (zona de desenvolvimento real), devendo possibilitar que os conhecimentos que ainda estão em processo de amadurecimento sejam antecipados (zona de desenvolvimento proximal).

Sobre "o que ensinar" se faz necessário que o profissional de Educação Física conheça as diferentes manifestações da cultura corporal do movimento possíveis de serem trabalhadas no âmbito escolar, como os blocos de conteúdos propostos pelos Parâmetros Curriculares Nacionais - esportes, ginástica, lutas e jogos; atividades rítmicas e expressivas; conhecimento sobre o corpo $^{3,7}$ e outros conhecimentos apresentados nos últimos anos Práticas Corporais Alternativas $;{ }^{8}$ atividades circenses, ${ }^{9}$ atividades radicais ${ }^{10}$ dentre outras.

E, ainda, é necessário entender que cada um dos conhecimentos acima mencionados pode ser subdividido em conformidade com suas variações, que, especificamente em relação ao objeto central deste artigo (jogo), pode variar de acordo com as fases de desenvolvimento cognitivo - jogos simbólicos, jogos de construção e jogos de regras, ${ }^{4}$ características do jogo ${ }^{2}$ e objetivos almejados, ${ }^{11}$ não se limitando a eles.

Partindo do pressuposto da existência de fases de desenvolvimento cognitivo, Piaget ${ }^{4}$ propôs a classificação dos jogos em de exercícios (ações simples, destituídas de intencionalidade, com exploração do próprio corpo), jogos simbólicos (faz de conta e imitações de papéis, 
personagens, animais e pessoas) e jogos de construção (jogos de competição, envolvendo um conjunto de regras), sendo que cada uma dessas classificações ainda sofre subdivisões.

Em Caillois, ${ }^{2}$ o jogo é classificado em Agôn (competição), Alea (sorte), Mimicry (simulacro) e Llinx (vertigem) e tem como objetivo a demonstração da excelência em um determinado domínio em ambientes em que a igualdade de oportunidades é dada a todos. O Agôn é caracterizado por jogos envolvendo a rivalidade entre indivíduos - ou equipes -, podendo se manifestar tanto por jogos e desportos de competição quanto por esportes de destreza. Diferentemente do Agôn, que está relacionado à conquista por mérito, via habilidade de quem joga, o Alea (sorte) não depende do jogador, mas sim de se lançar ao destino e ser contemplado pela sorte, arriscando-se em apostas. Por sua vez, os jogos de Mimicry (simulacro) são caracterizados por aspectos relacionados à imaginação, ou seja, pela incorporação fictícia de personagens e ações típicas delas, por um determinado momento e, nesse momento, crendo e fazendo crer que se trata de uma outra pessoa. Já a Llinx (vertigem) se manifesta pela desestabilização da percepção por algum instante, com um sentido de desorientação temporal. Exemplificando, as classificações de jogos propostos por Caillois ${ }^{2}$ podem ocorrer nas aulas de Educação Física, por meio de jogos pré-esportivos (competição), pela definição de quem inicia o jogo com a bola - par ou impar - e jogos como jokempô (sorte), pela dramatização, imitação e incorporação de personagens - profissões, super heróis, animais, dentre outros (imitação) e pela desestabilização temporal que precede o jogo de cabra cega e por piruetas.

Por sua vez, Krebs, ${ }^{11}$ classificando os jogos em conformidade com os objetivos das aulas***, propõe que estes sejam divididos em "de baixa organização" (de baixa complexidade, enfatizando o trabalho das noções espaciais e temporais básicas) e "jogos pré-esportivos" (aumento gradativo da complexidade das atividades, com a inclusão de regras mais complexas). Os jogos de baixa organização são subdivididos em quatro tipos: jogos de corridas variadas (exploração espacial ampla), jogos de linha (exploração de direções e sentidos), jogos de círculo (exploração de espaços fechados) e jogos de interpretação (exploração de formas e figuras). Já os jogos pré-desportivos, são subdivididos em dois: jogos

\footnotetext{
*** A proposta do autor não se resume às duas classificações de jogos apresentadas, se estendendo também às atividades rítmicas, de postura e locomoção e de autocontrole, não trabalhados no presente texto por não apresentarem relação direta com os jogos.

Conexões: revista da Faculdade de Educação Física da UNICAMP, Campinas, v. 10, n. 3, p. 87-100, set./dez. 2012.

ISSN: 1983-9030
} 
de destrezas fechadas (estímulo do ambiente se mantém constante) e jogos de destrezas abertas (estimulo do ambiente são alterados).

Conhecendo as principais características dos alunos com quem se está trabalhando e as possibilidades de manifestações da cultura corporal do movimento possíveis de serem trabalhadas, é indispensável utilizar estratégias de ensino que considerem as particularidades locais dos alunos, ou seja, torna-se importante que os conhecimentos que os alunos possuem do contexto extra-escolar também sejam valorizados, pois, conforme salienta Sacristán ${ }^{12: 9}$ "não tem sentido renovações de conteúdos sem mudanças de procedimentos e tampouco uma fixação em processos educativos sem conteúdos de cultura".

Dentre as estratégias de trabalho com os jogos circunscritos à escola, que valorizam o conhecimento dos estudantes e a sua participação no processo pedagógico, podemos citar os procedimentos metodológicos propostos por Rangel e Darido, ${ }^{13}$ que dividem o trabalho com os jogos em três perspectivas didáticas: o jogo jogado (reprodução de jogos transmitidos de geração para geração), o jogo transformado (a partir dos jogos já conhecidos, discutindo-os e propondo-lhes alterações com os alunos) e o jogo criado (invenção de novas formas de jogar, com novos objetivos, regras, formas de organização, materiais e tempo de jogo). Todavia, além dessas três perspectivas apresentadas pelas autoras, entrevemos, ainda, a possibilidade de inclusão de um quarto elemento, o jogo ampliado, que, numa sequência didática, se encaixaria entre o jogo jogado e o jogo transformado, estruturando-se em jogo - jogado, ampliado, transformado e criado. O jogo ampliado consistiria na introdução de novas formas de jogos obtidos na literatura e trazidos pelo docente com o intuito de ampliar o repertório lúdico infantil, que, com o tempo, poderão ser incorporados ao rol dos jogos jogados. ${ }^{14}$

Essa proposta didática ampliada de trabalho com os jogos nos parece bastante interessante, uma vez que, por intermédio dos jogos jogados, os conhecimentos advindos da cultura de cada estudante ganha espaço no âmbito escolar, o que pode favorecer seu interesse em participar e se envolver com essa disciplina; o jogo ampliado contribui para a incorporação de novos conhecimentos e valores, favorecendo o enriquecimento da cultura infantil; os jogos transformados estimulam a participação ativa dos estudantes não somente do ponto de vista fisiológico, mas também intelectual. Desse modo, propiciando que esses estudantes exercitem sua criatividade com a proposição de modificações e estratégias de alteração nos jogos já 
conhecidos, e os jogos criados respeitam as crianças como produtoras de cultura, ou seja, como indivíduos capazes de criar seu próprio jogo.

Ainda, entendemos que o trabalho com os jogos nas aulas de Educação Física pode ser pautado nos estilos "ensino por descoberta orientada" e "resolução de problemas", propostos por Mosston, ${ }^{15}$ que reconhecem os alunos como agentes centrais do processo educacional. No estilo de ensino por descoberta orientada, o docente exerce a função de mediador e incentivador do processo educacional, favorecendo a participação dos estudantes na decisão e na elaboração de respostas por intermédio de interrogações e estímulos. Já no estilo de ensino por resolução de problemas, sejam eles espontâneos (decorrentes de conflitos das relações humanas de forma voluntária) ou problemas suscitados pelo docente (criar um problema e auxiliar os estudantes a construírem possíveis resoluções). ${ }^{16} \mathrm{O}$ problema

“[...] permite a descoberta, a partir de elementos de base conhecidos (pesquisa de variantes a partir do ensino de uma dificuldade) [...] debates entre os alunos ou entre os alunos e o professor, com o objetivo de provocar reflexões e evocações". ${ }^{16: 61}$

De acordo com o exposto, ficam evidenciados alguns dos diferentes conhecimentos que o docente de Educação Física necessita possuir para conduzir seu trabalho e incluir como processo educativo o jogo no âmbito escolar. Contudo, resta tratarmos dos motivos que podem fundamentar a perspectiva de trabalhar com o jogo, conforme abordado no tópico a seguir.

\section{O jogo e suas possibilidades co-educativas}

As justificativas sobre o "porquê trabalhar com jogos nas aulas de Educação Física" são diversas, podendo a argumentação concernente à sua importância ir dos benefícios ao desenvolvimento psicomotor, ${ }^{17}$ perpassando pelo desenvolvimento motor, ${ }^{18}$ pelas contribuições à promoção da saúde, ${ }^{19}$ dentre várias outras perspectivas possíveis que, situadas num espaço/tempo e perspectiva de ser humano/sociedade/mundo, devem ser respeitadas. No entanto, optamos, neste ensaio, por trabalhar o jogo na perspectiva da co-educação, entendendo-a não como uma responsabilidade "apenas do" profissional de Educação Física, mas "também" dele, assim como de todos que atuam na educação. Dito de outra forma, a coeducação figura como objetivo geral da educação, abrangendo todas as disciplinas escolares e se manifestando nas estratégias metodológicas utilizadas pelos docentes. 
Assim, pensar a co-educação como uma possibilidade no cotidiano das aulas de Educação Física, implica assumir um passo adiante do que já se realiza há muito tempo: as aulas mistas. Trazer as diferenças para o convívio do processo educativo sem assumi-las como dado de realidade não resulta em co-educação, pois essa possibilidade exige que a percepção e o respeito à diversidade sejam o eixo do processo educativo.

Podemos iniciar diferenciando aulas mistas e co-educação ao apresentar a realidade existente na Educação Física escolar brasileira há algumas décadas: a que traz meninos e meninas para aulas na mesma turma e momento. A presença de ambos os sexos na mesma turma e momento caracteriza a aula como mista, no entanto, esta só será co-educativa à medida que os processos incluírem a atuação conjunta em jogos, atividades esportivas, lutas, danças e ginásticas para ambos os gêneros, de modo simultâneo e interdependente. Propor atividades diferenciadas para meninos e meninas é contentar-se com um processo educativo que não toma a sério a questão das relações de gênero e os processos de organização simbólica da cultura que estigmatizam determinadas práticas como próprias e outras impróprias para cada sexo, com base nas construções e relações de poder de gênero, estabelecidas na cultura e ao longo da história. ${ }^{20}$

Ainda que seja necessário aprofundar o aspecto das relações de gênero, cabe, logo de início, ampliar a concepção de co-educação para outras vertentes significativas das relações sociais de poder que se entrecruzam com gênero, ou seja, as relações étnicas, de classe, de idade, de necessidades educacionais especiais, de deficiências. Nesse sentido, é importante ampliar o conceito de co-educação, do âmbito em que, via de regra, tem sido tratado, a superação das aulas mistas por sexos. A exigência atual é enfrentar, todas as discriminações e exclusões a que meninos e meninas são submetidos pelas pré-determinações culturais sobre sua composição bio-fisiológica, para avançar - no sentido de uma co-educação como espaço e lugar de vivenciar a diversidade como exigência das relações humanas.

Isso implica trabalhar com processos em que não basta propor a igualdade de acesso, mas a equidade nas relações sejam elas de gênero, de etnia, de classe, de necessidades especiais, entre outras. Os estereótipos sexuais, étnicos, de classe, de deficiências, que marcam a corporeidade, estão fortemente arraigados ao cotidiano das pessoas e são vividos na Educação Física. 
A resistência, encontrada muitas vezes nas propostas co-educativas, está relacionada ao fato de que é necessário enfrentar um arcabouço cultural em que a marginalização do diferente é mais tranquila, ainda que esta se faça de modo sutil, como a sugestão de que os estudantes são livres para assistirem aos colegas se não desejarem participar da atividade central da aula (o jogo, ou outro conteúdo selecionado), ou mesmo, que podem usar algum outro material para uma atividade paralela não orientada. Quando isso ocorre, não raras vezes, as meninas, os menos habilidosos, os mais gordinhos, os que correm menos, os que não têm calçados adequados, os que têm alguma deficiência ficam de fora do jogo (por exemplo, o futebol ou o futsal que se pratica muito nas aulas de Educação Física Escolar).

O cotidiano da Educação Física apresenta mais fortemente o processo de agrupação das diferenças, sem uma proposta efetivamente co-educativa. A concepção de corporeidade construída e reconstruída em uma determinada sociedade tende a conceber que as habilidades para determinadas práticas pairam exclusivamente no contexto biológico, quando essas estão culturalmente influenciadas pelo estilo de vida, pela classe social, pelas questões étnicas, entre outros fatores sócio-políticos e/ou sócio-econômicos que, não raras vezes, transformam as diferenças em condições de desigualdade, legitimando-as em afirmações científicas parciais. O processo de organização cultural e todo o processo de aprendizagem desde a primeira infância faz do brincar, do vestir, do falar, do se comportar, do desejar... um conjunto imenso de representações sociais do comportamento esperado em uma determinada sociedade. Superar os processos de empoderamento e desempoderamento de uns em relação a outros grupos sociais é o desafio de um processo co-educativo.

Portanto, acreditamos que a função principal das aulas de Educação Física escolar consiste em ser um espaço estimulador de uma gama ampla de movimentos capazes de desenvolver nos estudantes os seus aspectos motores, afetivos, emocionais, sociais, culturais, cognitivos, oportunizando uma variabilidade de opções em conteúdos, dentre eles o jogo, que propiciem a inclusão e a diversidade, respeitando a individualidade e a diversidade como elemento construtor da experiência humana no mundo.

Assim, a termo de exemplo, nos arriscamos a apresentar algumas possibilidades, que não têm a pretensão de figurar como modelos, mas de se lançar no campo das possibilidades, a fim de que possamos refletir sobre maneiras de intervenção. 
No que tange às questões de gênero, o docente, de forma proposital, organiza a turma, em conformidade com o sexo e em dois grupos, expõe aos escolares que a atividade consiste num pré-esportivo que trabalhará com as diferentes formas de passes com as mãos (dimensão procedimental). Contudo, salienta que, ao longo da atividade, gostaria da participação do grupo na construção das regras e quem se sentir prejudicado pode pedir para paralisar a atividade e expor sua percepção sobre o que está ocorrendo e que, logo após, o grupo discuta intervenções que possam solucionar ou amenizar o problema. Para tanto, também de forma intencional, o docente passará aos estudantes as mínimas regras possíveis (cada grupo, um por vez, deverá trocar passes, contando em voz alta cada um, a fim de conseguir a maior quantidade de passes. A outra equipe, por seu turno, deverá interceptar o passe e tomar a posse da bola, o que permitirá a inversão de papéis). Caso os estudantes, ao longo da atividade, não peçam para paralisar o jogo nem reivindiquem mudanças, é papel docente questioná-los sobre aspectos relevantes, tais como a agressividade, a manutenção da posse de bola apenas entre poucos estudantes, a não participação efetiva de quem apresenta pouca habilidade motora, a exclusão das meninas etc., com o objetivo de que eles se manifestem e reflexões sejam feitas a respeito da criação de regras que tornem a atividade mais justa e democrática.

Um jogo importante para trabalhar as questões relacionadas ao gênero e sua relação com as construções socioculturais do que é adequado a homens e mulheres é o futpar, mas antes mesmo de sua ocorrência, os estudantes poderiam ser convidados a refletir sobre os estereótipos de gênero no jogo através da leitura do texto "Faca sem ponta galinha sem pé" de Ruth Rocha, que contextualiza de forma bastante lúdica e interessante como essa teia é tecida e reproduzida na formação das pessoas desde a infância.

A partir dessa tematização inicial, o futpar ocorrerá através da formação de duas equipes, nas quais seus integrantes serão compostos por duplas, preferencialmente meninos e meninas, que deverão se deslocar por todo espaço de jogo de mãos dadas e em duplas também realizam a função de goleiros. A partir dessa organização inicial, o jogo é realizado com as mínimas regras do futebol, estipulando apenas a proibição de: não poder tocar a bola ou conduzi-la com as mãos, empurrar ou calçar o adversário e soltar as mãos. Reforçando a idéia de que as duplas deverão se deslocar de mãos dadas, inclusive ao receber, passar, driblar ou chutar a 
bola ao gol. Esse tipo de jogo é oportuno para que no seu decorrer meninos e meninas despertem o respeito às diferenças e busquem em conjunto situações para superá-las; para que haja maior interação e trocas de passes; maior socialização da posse de bola, dentre outras situações. Contudo, ela não está imune a que exageros e problemas ocorram, o que percebemos como fator positivo, pois estes se levados aos estudantes e problematizados, fazendo com que eles próprios discutam e criem possibilidades para resolverem os problemas, também figuraram como um processo co-educativo. No próprio futpar, outras parcerias podem ser experimentadas para incentivar o respeito e o conhecimento da diversidade étnica, de necessidades educacionais especiais, de classe, de níveis de habilidades, de composição corporal, entre outras.

Um jogo que pode figurar como co-educativo em relação ao respeito às crianças com deficiência visual, pode ser o "robô". Esse jogo consiste na formação de duplas, em que ambos irão combinar símbolos que se traduzirão em comandos para andar, parar, virar à direita e virar à esquerda. A partir da combinação desses signos, o estudante que fará a função de "robô" deverá por uma "venda" nos olhos e se locomover apenas a partir dos comandos dados por seu parceiro. Após a vivência das funções de "robô" e operador de "robô", as funções devem se inverter, possibilitando que todos vivenciem as mesmas funções. Esse jogo além de possibilitar a inclusão de alunos com deficiência visual nas aulas de Educação Física, também favorece a formação de conceitos e de respeito às pessoas com deficiência, o desenvolvimento da autoconfiança entre os pares e a comunicação pela cinestesia corporal.

Desta forma, entendemos que a Educação Física, por intermédio do jogo co-educativo, pode trazer significativas contribuições à formação de uma sociedade equânime, que valorize e respeite a diversidade humana.

\section{REFERÊNCIAS}

${ }^{1}$ HUIZINGA, J. Homo ludens: o jogo como elemento da cultura. São Paulo: Perspectiva, 1971.

${ }^{2}$ CAILLOIS, R. Os jogos e os homens: a máscara e a vertigem. Gallimard, 1967.

${ }^{3}$ BRASIL. Ministério da Educação e Cultura. Secretaria da Educação Fundamental. Parâmetros Curriculares Nacionais: Educação Física. Brasília: MEC/SEF, 1997.

Conexões: revista da Faculdade de Educação Física da UNICAMP, Campinas, v. 10, n. 3, p. 87-100, set./dez. 2012.99 ISSN: 1983-9030 
| ${ }^{4}$ PIAGET, J. A formação do símbolo na criança. São Paulo: Zahar, 1971.

${ }^{5}$ GAllahue, D. L.; OZMUN, J. C. Compreendendo o desenvolvimento motor: bebês, crianças, adolescentes e adultos. São Paulo: Phorte, 2003.

${ }^{6}$ VYGOTSKY, L. S. A formação social da mente: o desenvolvimento dos processos psicológicos superiores. São Paulo: Martins Fontes, 1984.

${ }^{7}$ BRASIL. Ministério da Educação e Cultura. Secretaria da Educação Fundamental. Parâmetros Curriculares Nacionais: Educação Física. Brasília: MEC/SEF, 1998.

${ }^{8}$ COLDEBELlA, A. O. C.; LORENZETTO, L. A.; COLDEBELLA, A. práticas corporais alternativas: formação em Educação Física. Motriz, Rio Claro, v. 10, n. 2, p. 111-122, 2004.

${ }^{9}$ BORtOleto, M. A. C.; CAlCA, D. H. Circo e Educação Física: compendium das modalidades aéreas. Movimento \& Percepção, Espírito Santo do Pinhal, v. 8, n. 11, p. 345$360,2007$.

${ }^{10}$ ARMBRUST, I.; PEREIRA, D. W. Pedagogia da aventura. Jundiaí, SP: Fontoura, 2010.

${ }^{11}$ KREBS, R. J. Considerações organizacionais para a Educação Física nas séries inicias do ensino fundamental. Cinergis, v. 1, n. 1, p. 19-38, 2000.

${ }^{12}$ SACRISTÀN, J. G. O currículo: uma reflexão sobre a prática. 3. ed. Porto Alegre: ArtMed, 1998.

${ }^{13}$ RANGEL, I. C. A.; DARIDO, S. C. Jogos e brincadeiras. In: DARIDO, S. C.; RANGEL, C. A. (Ed.). Educação Física na escola: implicações para a prática pedagógica. Rio de Janeiro: Guanabara Koogan, 2005. p. 155-175.

${ }^{14}$ SILVA, J. V. P.; SAMPAIO, T. M. V. Jogos tradicionais: reprodução, ampliação, transformação e criação da cultura corporal do movimento. Revista Brasileira Ciência e Movimento, Brasília, v. 19, n. 1, p. 72-86, 2011. 
${ }^{15}$ MOSSTON, M. La enseñanza de la Educacion Física. Buenos Aires: Paidós, 1982.

${ }^{16}$ FARIA JUNIOR, A. G.; CORREA, E. S.; BRESSLANE, R. S. Prática de ensino em Educação Física, estágio supervisionado. Rio de Janeiro: Editora Guanabara, 1987.

${ }^{17}$ LE BOULCH, J. O desenvolvimento psicomotor: do nascimento até 6 anos. Porto Alegre: Artes Médicas, 1984.

${ }^{18}$ TANI, G. et al. Educação Física escolar: fundamentos de uma abordagem desenvolvimentista. São Paulo: EPU/EDUSP, 1988;

${ }^{19}$ FARINATTI, P. T. V.; FERREIRA, M. S. Saúde, promoção da saúde e Educação Física: conceitos e aplicações. Rio de Janeiro: Ed. da UERJ, 2006.

${ }^{20}$ SAMPAIO, T. M. V. Gênero e lazer: um binômio instigante. In: MARCELLINO, N. C. (Org.). Lazer e Sociedade, múltiplas relações. Campinas: Alínea, 2008. p. 139-154. 